\title{
Desarrollo Socio-Histórico de la Enfermería en la Cultura de la República Popular China ${ }^{1}$
}

\section{Institución: Universidad de Costa Rica}

\author{
Ana Guzmán Aguilar ${ }^{2}$ \\ Brian Iván Barley López ${ }^{3}$ \\ Franklin Blanco Solano ${ }^{4}$ \\ María Fernanda Piedra Hernández ${ }^{5}$ \\ Keilor Steven Solórzano Taleno ${ }^{6}$
} ENSAYO

\section{COMO CITAR}

Guzmán, A.; Barley, B.; Blanco, F.; Piedra, M.; Solórzano, K. (2013). Desarrollo Socio-Histórico de la Enfermería en la Cultura de la República Popular China. Rev. Enfermería Actual de Costa Rica, 25, 1-16. Recuperado de: $<$ http://www.revenf.ucr.ac.cr/china.pdf $>$ ISSN 1409-4568

\section{RESUMEN}

Se presenta una revisión bibliográfica acerca de algunos de los orígenes de la enfermería en la actual República Popular de China. Entre los principales objetivos se encuentra describir el desarrollo socio-histórico de enfermería en la cultura de la República Popular de China, en específico, identificar sus orígenes como disciplina en la cultura, distinguir la influencia de los patrones culturales chinos en el desarrollo de la práctica laboral de dicha disciplina y, por último, señalar los avances de la Enfermería como disciplina desde la visión de China en la actualidad. Asimismo, para la recolección de datos se emplearon artículos publicados en revistas de enfermería, páginas web de la cultura china, libros referenciales y una entrevista a un profesional exmiembro del gobierno chino, con amplio conocimiento de esta cultura. La Fundación filosófica china del taoísmo y la tradición estética, en combinación con la ciencia occidental, serán relevantes para los futuros avances en la investigación de enfermería y los patrones educativos de la sociedad china son ejemplares en cuanto a su desarrollo, ampliación, planificación y establecimiento en la población en general. Se concluye que las filosofías y religiones chinas han influido fuertemente en la forma de vivir y pensar respecto de la salud y su cuidado dentro de la sociedad China.

Palabras clave: Cultura-China, Desarrollo-Sociohistórico-Enfermería, Enfermería-Histórica

\footnotetext{
${ }^{1}$ Fecha de recepción: 25 de Junio $2013 \quad$ Fecha de aceptación: 26 de agosto 2013

${ }^{2}$ Profesora. Escuela de Enfermería. Universidad de Costa Rica. Correo electrónico: anaguz2610@yahoo.com

${ }^{3}$ Estudiante. Escuela de Enfermería, Universidad de Costa Rica. Correo electrónico:brian_7000@hotmail.com

${ }^{4}$ Estudiante. Escuela de Enfermería, Universidad de Costa Rica. Correo electrónico: franklin.blanco@ucr.ac.cr

${ }^{5}$ Estudiante. Escuela de Enfermería, Universidad de Costa Rica. Correo electrónico:mariaferpiedra@hotmail.com

${ }^{6}$ Estudiante. Escuela de Enfermería, Universidad de Costa Rica. Correo electrónico: keilor_solorzano25@hotmail.com
} 


\title{
Socio-Historical Development of the Nursing in the Culture of the People's Republic of China ${ }^{7}$
}

Institution: Universidad de Costa Rica

\author{
Ana Guzmán Aguilar ${ }^{8}$ \\ Brian Iván Barley López ${ }^{9}$ \\ Franklin Blanco Solano ${ }^{10}$ \\ María Fernanda Piedra Hernández ${ }^{11}$ \\ Keilor Steven Solórzano Taleno ${ }^{12}$
}

ESSAY

\section{CITED}

Guzmán, A.; Barley, B.; Blanco, F.; Piedra, M.; Solórzano, K. (October 2013). Socio-Historical Development of the Nursing in the Culture of the People's Republic of China. Rev. Enfermería Actual de Costa Rica, 25, 1-16. Recuperado de::

$<$ http://www.revenf.ucr.ac.cr/china.pdf $>$ ISSN 1409-4568

\begin{abstract}
This essay presents a literature about some of the most remarkable origins of nursing in today's people's Republic of China The main objectives around this topic were pursued to describe the socio-historical development of nursing in the culture of the people's Republic of China, specifically identify their origins as a discipline in the culture, to distinguish the influence of Chinese cultural patterns in the development of the nursing labor practice, and finally show the advance of nursing as a discipline from China vision against nowadays world vision. At the same time, for data collection sources were used journal articles on nursing, web pages about Chinese culture, reference books and an interview with a professional exmember of the Chinese government with extensive knowledge about this culture. Both the Foundation of Chinese philosophical tradition of Taoism and aesthetics in combination with western science will be important for future developments in nursing research and educational patterns of Chinese society, being altogether exemplary in terms of its development, expansion, planning and establishment in the general population. Henceforth was concluded that Chinese philosophies and religions have strongly influenced the way they live and think about the health and care within Chinese society.
\end{abstract}

Keywords: Culture-China, Development-Sociohistorical-Nursing, Nursing-Historical

\footnotetext{
${ }^{7}$ Date of receipt: June 25, 2013

Date of acceptance: August 26, 2013

${ }^{8}$ Professor School of Nursing. Universidad de Costa Rica. Correo electrónico: anaguz2610@yahoo.com

${ }^{9}$ Student. School of Nursing, Universidad de CostaRica. Correo electrónico:brian_7000@hotmail.com

${ }^{10}$ Student. School of Nursing, Universidad de CostaRica. Correo electrónico: franklin.blanco@ucr.ac.cr

${ }^{11}$ Student. School of Nursing, Universidad de Costa Rica. Correo electrónico: mariaferpiedra@hotmail.com

${ }^{12}$ Student. School of Nursing, Universidad de Costa Rica. Correo electrónico: keilor_solorzano25@hotmail.com
} 


\section{INTRODUCCIÓN}

La Enfermería es una de las más recientes disciplinas encontradas alrededor del mundo, cuyos orígenes se ubican en distintas sociedades antiguas; no obstante, según Donahue (1993), fue en los albores de la primera era cristiana que la doctrina de Cristo del amor y la fraternidad no solo transformó la sociedad, sino que promovió el desarrollo de la enfermería, del que se infiere que la "enfermería organizada", consecuencia directa de estas enseñanzas, traducía el concepto de altruismo puro introducido por los primeros cristianos. Las obras de misericordia abarcaban las necesidades humanas básicas, reconocían tales necesidades en grupos diversos dentro de una misma sociedad y reflejaban el deseo de compasión humana. Un significado espiritual se unió estrechamente al cuidado de los enfermos y los que sufren. Este florecimiento de idealismo cristiano tendría para siempre un impacto profundo y relevante en la práctica de la enfermería (Donahue, 1993).

Estas circunstancias permitirían luego la redefinición de la enfermería con la labor desempeñada por Florence Nightingale, por la aceptación de su trabajo con los enfermos y la implementación de características propias de esta disciplina. Dicha ideología se expandió por muchos lugares del continente con la ayuda de misioneras o personas de la caridad, recorrido en el que toparon con una población distinta desde el punto de perspectiva occidental, con sus costumbres bien definidas y patrones de salud marcados por el naturalismo y misticismo.

La República Popular de China, según Smith y Tang (2004), cuenta con una población de 1,3 millones de personas que viven en una superficie de alrededor de 10000 000km2, por ello es el país más poblado del mundo. Desde finales de 1970, las reformas políticas y sociales han cambiado de forma radical el esquema económico del país, incluyendo la agricultura a la manufactura. La industrialización ha generado prosperidad relativa, con un gran crecimiento económico, aunque también la salud y el nivel de vida se beneficiaron de dichos cambios: la esperanza de vida media al nacer es de alrededor de 70 años para los hombres y 73 años para las mujeres, con una mortalidad infantil de 157 por cada 1000 nacimientos de varones y 106 por cada 1000 nacimientos para las mujeres (OMS, 2004).

Según Watt (2004, citado por Smith y Tang, 2004), el tratamiento de salud chino fue proporcionado tradicionalmente por diversos miembros del personal paramédico y médico, aunque en muchas ocasiones los mismos miembros de la familia se encargaban de la distribución del cuidado diario de sus familiares enfermos. En sus inicios, la profesión de la enfermería en realidad no existía en absoluto, máxime considerando las divergencias entre patrones culturales e históricos, razón que motiva estudiar el desarrollo de la Enfermería, profesión enfocada al cuidado integral de la persona, en el cual se emplean conocimientos básicos médicos para promover la salud y el bienestar en una población.

A finales de 1930, según Smith y Tang (2004), la enfermería que había entrado en vigor en China en la década de 1880 se había convertido en una profesión representada por una asociación nacional bien organizada con una membresía de 6000 enfermeros, la cual se expandió hasta ser integrada por cientos de nuevos reclutas formados en casi 200 escuelas de enfermería de todo el país. 
El crecimiento mencionado fue notable y, en retrospectiva, fue gracias a la contribución de médicos misioneros occidentales que la profesión nació como tal y se expandió, al punto de que muchos enfermeros se entrenaron con esos misioneros y fundaron hospitales a partir de nada.

Aunque el número de médicos misioneros, médicos y enfermeras era pequeño comparado con el tamaño de la población del país, ya pesar de su interés en "la curación de los enfermos" con el objetivo de servir a su objetivo principal de "salvar el alma", su contribución al desarrollo de la enfermería en China, en especial, sus esfuerzos en la formación de enfermeras nativas en numerosos hospitales de misioneros y escuelas de enfermería no se puede subestimar.

En cuanto a su geografía, las zonas del interior eran más propensas a la xenofobia y prevalecía el anticristianismo, mientras quelas zonas costeras recibían mejor las nuevas ideas y técnicas traídas por los misioneros occidentales. Toda esta perspectiva en conjunto crea un marco contextual para admirar la fuente motivadora e impulsora de la enfermería en ese país, temática que no ha sido abordada y que, por ende, justifica la elaboración de este trabajo.

Este ensayo presenta un breve recorrido sociohistórico sobre la evolución de la enfermería en China hacia la actualidad, iniciando con la incursión del modelo de Florence Nightingale a mediados del siglo IXX, la apertura a esta nueva profesión, los desafíos que enfrentaron en el lenguaje y las creencias religiosas para adaptarse al modelo de comportamiento y la cultura hasta la situación actual que viven los y las enfermeras en china.

\section{DESARROLLO}

\section{Raíces de una profesión occidental}

Según Smith y Tang (2004, pp.16-17), la enfermería moderna de china evolucionó, debido a la influencia de los misioneros occidentales que comenzaron a llegar después de que China perdió la Guerra del Opio en 1842 ( Xu et al., 2000); no obstante, tiempo antes, en1835, el primer influjo occidental en un centro hospitalario se registró en Cantón. La primera enfermera estadounidense, Elizabeth McKechnie, llegó en 1884 y comenzó a introducir el sistema de Florence Nightingale de la enfermería; luego, en1888, Ella Johnson, otra estadounidense, abrió la primera escuela de enfermeras chinas en Fuchou (Chan y Wong, 1999). Más tarde, en 1910, Nina Gage estableció un programa de formación de enfermeras como parte de la misión de Yale (Xu y et al., 2000); tiempo después, entre 1912 y 1914, se desempeñó como presidente de la Asociación de Enfermería China.

En 1915, China estableció un sistema de exámenes para la certificación profesional del personal de enfermería, seguido por la primera licenciatura. En 1923, el 53\% de las camas de hospital eran atendidas por misioneros. Los enfermeros misioneros constituyeron el 32\% del total de enfermeras en China, en 1923, y su número llegó a casi 700 en 1927. El enfoque de compromiso derivado del misionero fue otro factor determinante en el rápido avance de la enfermería, el cual desembocó en el origen de la Asociación de Enfermeras de China. A partir de dicho momento, surgió una etapa crítica del desarrollo de la enfermería en el país, puesto que la AEC organizó la profesión y reguló su formación a través de registro de patrocinio, la 
celebración de los exámenes y el desarrollo de un plan de estudios estándar; es decir, fungió como un gran organizador y allanó el camino para un mayor crecimiento de la profesión.

Derivado del desarrollo político en China, el encausamiento de los misioneros llegó a su máximo con la represión de la revuelta de Boxer y el derrocamiento de la monarquía dinástica y decayó con el recrudecimiento de la xenofobia o el nacionalismo, impidieron cualquier forma de agitación política masiva.

\section{Inserción de la cultura china en el origen de la Enfermería}

Las características morales exigidas en las enfermeras se ligan a la cultura china; por lo tanto, muy familiar para la mayoría de los chinos y las enfermeras chinas tienen una obligación moral de tratar a los pacientes con sinceridad (Pang, 1998, citado en Smith y Tang, 2004). Otra creencia cultural se refiere a un tema común definido por la relación jerárquica con otros que, desde el confucionismo, se refieren a las relaciones entre padres e hijos, en cuanto a las reglas y los sujetos, el marido y la mujer, las personas mayores y jóvenes, y la relación entre amigos (Wong y Pang, 2000, citado en Smith y Tang, 2004).

El orden social se mantiene cuando todos los miembros de la sociedad respetan dichas relaciones. La unidad familiar es uno de los ejes centrales en la tradición y las creencias chinas; por ende, desempeña un papel clave en la estructura de la sociedad china. Por tradición, la toma de decisiones en cuanto a temas de salud y atención de parientes enfermos reside en los miembros de la familia; entonces, el que una enfermera ajena atienda a los enfermos chinos resulta una paradoja. En este sentido, Pang y et al.(2000, citados por Smith y Tang, 2004), comentan que las enfermeras pueden introducirse conceptualmente al ámbito de la familia de los pacientes e incluso actuar como un miembro de la familia sustituta, lo cual aumenta la confianza en el paciente de régimen terapéutico y ayuda a superar el estigma por ser cuidado por un extraño.

La medicina china y la ética de enfermería también se entrelazan con la doctrina confuciana, cuya norma moral para los cuidadores es similar a la esperada de una persona confuciana ideal (Tsai, 1999, citado en $\underline{\text { Smith y }}$ Tang, 2004); sin embargo, la ética de enfermería no siempre ha significado decir la verdad al paciente (Pang 1999, citado en Smith y Tang, 2004), aunque las enfermeras deben ser sinceras, puesto que los pacientes no pueden perder la confianza en su tratamiento, máxime si se trata acerca de conocer enfermedades graves. Todos estos cuestionamientos culturales influyen en el pensamiento, la práctica y la vida cotidiana de las enfermeras chinas desde su origen y asentamiento dentro de la sociedad.

\section{Apertura de oportunidades para el profesional de Enfermería}

Durante el primer par de años, según Chen (1996), la Asociación de Enfermeras Chinas fue vagamente organizada y existió incertidumbre en cuanto a su dirección, razón por la que la AEC decidió reorganizarse luego de un periodo de revoluciones, tras los cuales la señorita Gage fue elegida presidente, puesto que mantuvo hasta 1914.

Chen (1996), afirma que se pactaron múltiples reuniones para definir diversos asuntos de la organización en las que sus integrantes resolvieron que, en ausencia de una autoridad uniforme gubernamental, encargada de la formación de enfermería, el AEC se responsabilizaría por asuntos tales como el establecimiento de un estándar 
para todas las escuelas de enfermería en el país, la formulación de un modelo curricular y la aplicación de exámenes de certificación. En la reunión de1912, se decidió reunirse en una nueva convención nacional en Shanghai, la cual sería en 1914.

Chen (1996) comenta que en la conferencia de Shanghai, se otorgó un reconocimiento honorífico de la presidencia a la señorita Elsie Maw Fung Chung, graduada en el año 1909 del Guy’s Hospital de Londres y la primera enfermera china formada en el extranjero. Como no había ningún equivalente para la palabra "enfermera" en chino, la señorita Chung, mediante consulta previa a un número de sinólogos, eligió una de varias versiones en chino: el término chino hù- shì, que se compone de dos caracteres chinos:

\section{護士}

El primero, hù, significa "protección" o "cuidado", mientras que el segundo, shì, significa "sabio" o "técnico". A su vez, posee una connotación de persona con cierto grado de privilegio, dentro de la sociedad.

\section{La diferencia del lenguaje y creencias religiosas}

Según Meilian (2013), la mayor dificultad de trabajar en el extranjero se refiere a las barreras lingüísticas; al respecto, $\mathrm{Su}$, una enfermera China, menciona que al trasladarse a otros países 1 o s principales problemas son el lenguaje y la comunicación, experiencia que vivió en Arabia Saudita, lugar en el que, además, debió aprender cómo confortar a los pacientes en lo emocional, un aspecto difícil de expresar en el idioma chino. Su afirma que, a diferencia de China, en este nuevo lugar las enfermeras están dispuestas a proveer soporte emocional a los pacientes, un sentimiento totalmente nuevo para ella.

Sin embargo, es posible identificar patrones bien definidos en cuanto al desarrollo de una cultura formal y respetuosa, cuyas bases se cimentan en afirmaciones filosóficas, tal como lo aclara Chen (2002) en la siguiente idea:

Con base en la literatura y la observación directa de las diferentes corrientes políticas, la primera, conocida como la República de China, y la actual o segunda conocida como la República Popular de China, es evidente una introducción a las filosofías chinas, así como de su religión, creencias básicas y valores con un significado especial en cuanto a la salud y la enfermería. Las filosofías chinas y la religión incluyen principios de Confucio, así como del taoísmo, la teoría del ying y el yang y el budismo. Estas creencias y valores implican una manera de educación, como la práctica de acupuntura, tratamiento con hierbas y terapias en cuanto a la dieta, lo cual, al combinarse la medicina tradicional de las personas chinas y la ciencia occidental, se re direccionó el tratamiento de enfermería y s e estableció de una forma efímera en ese país (p.270).

Según Wong (2007), en la cultura tradicional China, los medicamentos y la medicación son vistos como una versión; por lo tanto, los medicamentos son ingeridos solo mientras haya síntomas y luego son descontinuados, máxime si los síntomas no son obvios. Aparte de las creencias culturales de los padres, los efectos secundarios menores de ciertos antibióticos promueven el incumplimiento de la medicación. 
El uso de "sobrantes", y los antibióticos "compartidos" y la sobre compra aleatoria de antibióticos por parte de los padres son situaciones comunes en la comunidad, debido a que, por la similitud de síntomas, piensan que sus hijos sufren las mismas enfermedades, entonces, les suministran "sobrantes" o antibióticos "compartidos" a sus hijos y solo los llevan al médico si no hay mejoría (Chang y Tang, 2006, citado por Wong, 2007). Lo anterior origina un deterioro en la salud de las personas que, a su vez, desemboca en la necesidad de recurrir a tratamientos más agresivos con efectos secundarios inesperados; a pesar del uso incorrecto de medicaciones y medicamentos, hay pequeños grupos de chinos que también culpan de la mala salud o sus desgracias a las fuerzas sobrenaturales, a un castigo divino o a la malevolencia deuna "bruja" o "hechicero"(Helman, 1994, citado por Wong, 2007), razón por la que recurren a la religión en busca de cura y protección.

Tal panorama obliga a que el consumo de medicamentos sea regulado de manera estricta, más si se considera que la automedicación puede generar consecuencias negativas para el organismo y, en lugar de controlarlos síntomas, pueden causar otros malestares. En la práctica de la enfermería se debe conocer los métodos adecuados para lograr que los pacientes terminen de consumir la medicación recetada, respetando la decisión del paciente en todo momento; aparte, cuando se recibe un paciente se le debe consultar acerca de si se automedicó antes de ingresar al centro hospitalario. Por otra parte, y ligado a la cultura, según Davison (2005), las enfermeras están obligadas a conocer acerca de las creencias chinas en los buenos espíritus, a los cuales se invoca en todo momento para remover los malos espíritus, para pedir protección o para sentirse mejor.

\section{Modelo de comportamiento y cultura de respeto}

Estos hechos filosóficos de muestran las implicaciones en cuanto al tratamiento médico de la población china, permeada por una fuerte cultura religiosa, hermética en cuanto a aceptar tratamientos artificiales, provenientes de culturas non gratas. En esta misma línea, se percibe la relevancia del lenguaje kinésico y del comportamiento, las cuales pueden ser irrespetuosas según sea el caso; por ejemplo, como enfermero o enfermera, se debería saber que es considerado irrespetuoso el intercambiar miradas con alguna otra persona. Un enfermero o enfermera no puede mirar a los ojos a un ciudadano chino mientras explica un procedimiento o les da instrucciones. Las personas chinas evitan el contacto visual en lugares atestados de personas para darles privacidad (Davison, 2005).

Como enfermero, en cuanto al cuidado dentro de la cultura China, es relevante saber que los chinos sienten un alto respeto por la autoridad, lo cual podría causar problemas en la comunicación dentro del cuidado de la salud, dado que, cuando una enfermera está explicando algo al paciente, este asiente o aprueba lo que se le explica. La enfermera puede pensar que el paciente está entendiendo, pero el paciente chino podría estar tratando de ser respetuoso hacia alguien que representa una figura de autoridad; ante estos casos es imprescindible que el enfermero trate de comprobar si tu paciente verdaderamente está entendiendo, y si es posible conseguir un traductor médico certificado (Lincona, Sánchez, Vásquez, Villanueva y Mak, 2010).

Según Chen (2002), los valores, creencias, religiones y filosofías de vida influyen en el cuidado de la salud de las personas. La cultura popular china se caracteriza por ser una cultura conservadora, con una amplia gama de costumbres y tradiciones; por consiguiente, están permeados por corrientes como el budismo, taoísmo, el ying-yang, el confucionismo, entre otros. Dado lo anterior, en la práctica de la enfermería, es necesario conocer el estilo de vida de las personas que se encuentran en cuidad, y respetar sus creencias religiosas y valores 
de vida; en el caso de la República Popular de China, se caracteriza por su apego a las tradiciones, las cuales influyen tanto en el modo de vida, como en el ejercicio de las profesiones, razón por la que es imperante respetar su modo de vida para establecer un equilibrio entre todas las aristas de la salud y facilitar la recuperación.

\section{Asentamiento de la Enfermería en China}

Bowers (1973), citado por Chang y Wong, considera que uno de los acontecimientos significativos que marcan el desarrollo de la enfermería en China acaeció en 1915, cuando la Peking Union Medical College (PUMC), junto a la Fundación Rockefeller de Estados Unidos establecieron un programa de educación médica en China y una escuela de enfermería situada en la PUMC. La escuela de enfermería buscó obtener el mismo grado de excelencia académica de la escuela de medicina de la PUMC, entidad que solo aceptaba estudiantes que hubieran cursado dos años de universidad como mínimo y que dominaran el idioma inglés: "Debido al énfasis en tan altos estándares de educación, los graduados han ocupado posiciones de liderazgo y han tenido un gran impacto en la educación y el servicio de enfermería en China" (Chan yWong, 1999; citado en Davis, 1992).

En 1922, la asociación china en enfermería llegó a formar parte del Consejo Internacional de Enfermeras(os) (Yu, 1989) y continuó siendo miembro hasta 1949, año en que los comunistas tomaron el poder en China. El área de la medicina continuó generando avances, mas la enfermería no recibió la misma atención. Tal como afirman Rae, Rim y Yu (2002) la guerra de liberación comunista de 1949 dejó a China con dificultades económicas, al punto de que, para el año 1952, la difícil reincorporación de la enfermería fue una tarea ardua. Para este momento China necesitaba acelerar la producción de un gran número de enfermeras que asumieran las responsabilidades que se presentaban por la falta de personal médico. Las enfermeras estaban para ayudar a controlar la alta prevalencia de muertes maternas e infantiles, la principal causa de muerte en China; en ese momento las enfermeras no solo eran consideradas no profesionales, sino que eran requeridas únicamente para "asistir" a los médicos (Rae, Rim y Yu, 2002).

Chang y Wong (1999) exponen otra de las crisis que sufrió la educación en el periodo 1967-1977, lapso en el que ocurre la Revolución Cultural China, tras la cual la educación fue considerada "no esencial" y se cerraron muchas escuelas de enfermería, de modo que la educación y la práctica de la disciplina retrocedieron en ese periodo, al punto de que, tal como añade Iammarino (1983), China se cerró al mundo de occidente y, en consecuencia, desaparecieron muchas escuelas y programas educativos. La educación superior disminuyó su número de nuevos estudiantes hasta el año 1970.

Una mayor estabilidad llegó a principios de 1980, una vez finalizada por completo la revolución, momento en el que el Gobierno chino se percató de la urgencia y la necesidad de desarrollar la enfermería, motivo por el cual decidieron reponer el tiempo perdido, tal como lo exponen Chang y Wong (1999).

\section{Estructuración de la Enfermería hasta la actualidad}

El panorama de la enfermería en China ha mejorado en las últimas décadas, puesto que, según Smith y Tang (2004), citado en Chang y Wong, (1999), se renovó el "título de bachillerato universitario", en 1983, gracias al establecimiento de un curso de enfermería en el Colegio Médico de Tainjin, institución que graduó su primera clase en 1988. 
Chang y Wong (1999), clasifican los tres niveles de educación básica en enfermería que existen en la actualidad en Escuelas de Salud, diploma universitario y título universitario, gracias a los que se formaron más de un millón de profesionales en enfermería en China, cifra que no incluye del año 2000 en adelante.

\section{Escuelas de salud}

Para Chang y Wong (1999), citado en Chiu y Lee (1996), las Escuelas de Salud integran la principal forma en que se brinda la formación en enfermería de China, en las cuales se forman alrededor de 40000 enfermeras(os) por año. Dichos centros de estudio funcionaban con programas certificados y producían técnicos en enfermería llamados husi, quienes dominaban la fuerza laboral en los hospitales de China. Estas escuelas podían ser Escuelas Junior en Salud, Escuela Técnica en Enfermería o Escuelas en Salud basadas en entrenamiento para enfermería.

La mayoría de dichas escuelas se encuentran adjuntas a hospitales. En cuanto al tiempo para formación de profesionales, este corresponde de tres a cuatro años, si se cursa el penúltimo año de educación de secundaria, mientras quede dos a tres años, si se trataba de estudiantes del último año de secundaria. Una vez finalizada la formación, los estudiantes que aprueben el examen estatal de enfermeras(os) o RN (por sus siglas en inglés), podrían laborar como enfermeros.

\section{Diploma universitario}

Según Chang y Wong (1999), el diploma universitario fue creado en 1980 y representa un nivel mayor de formación académica en comparación con el certificado que se obtiene en una Escuela de Salud: "Tras la finalización de los cursos, los estudiantes pueden ser con tratados en áreas tanto de enfermería clínica como enseñanza en enfermería. Estas instituciones forman alrededor de 1000 profesionales cada año" (Chang y Wong, 1999; citado en Chiu y Lee, 1996).

\section{Título universitario}

El título de bachillerato tiene una duración de cinco años. El principal requerimiento para esta modalidad consiste en título de secundaria o un certificado de Escuela de Salud tal como lo comentan Rae, Rim y Yu (2002); tras concluir dicha formación, los estudiantes pueden optar por puestos de trabajo en enfermería clínica, educación y puestos administrativos: "Para 1999 habían alrededor de 18 universidades médicas que ofrecían este tipo de título de bachillerato, pero en 2001 el número de instituciones que ofrece esta modalidad ha aumentado a 62" (Rae, Rim y Yu, 2002; citado en Shen, 2001).

La licenciatura en enfermería es considerada como un estudio para la élite, dado que toma cinco años de estudio y solo gradúa 300 enfermeras(os) por año; no obstante, China también cuenta con dos nuevos campos para el programa nacional de enfermería llamados Programa de Medicina China y el Programa de Lengua Extranjera. En el primero los estudiantes son entrenados para que se familiaricen con los principios de la medicina china (la mayoría quedan trabajando en este campo) y en el segundo, las lecciones son impartidas en idiomas extranjeros, usualmente inglés y japonés, con el fin de que se preparen para una carrera internacional. 
Los programas de posgrado se encuentran en desarrollo aunque el primero fue establecido en la Universidad Médica de Beijing en 1992, ya en el 2000 había alrededor de siete programas de posgrado.

Los criterios de admisión para estos programas son muy estrictos, dado que incluye exámenes escritos, experiencia clínica y demostración de varias habilidades en enfermería. Asimismo, según Xu (2002), el primer programa de doctorado en enfermería fue originalmente planeado para que empezara en el 2000, mas fue un intento fallido dado que no recibió apoyo del gobierno.

\section{La Asociación China de Enfermería}

La Asociación China de Enfermería (CNA) sirve como el principal cuerpo para unir, desarrollar y promover la enfermería, en principio, fundada en 1909 como la Sociedad de Enfermeras Chinas. Se encargar de proteger los derechos de los y las enfermeras, la difusión de conocimientos avanzados de enfermería y publicar artículos académicos.

\section{Ética y moral de la enfermería china}

La moral de la enfermería china refleja las creencias de los habitantes chinos y su entendimiento cultural acerca de la salud. "La medicina tradicional china se enfoca en el organismo humano, su lugar dentro del universo y su interacción son sus cinco fases evolutivas: madera, fuego, tierra, metal y agua. La enfermedad resulta de la desarmonía y ocurre cuando el cuerpo humano sale de su balance con su medio ambiente"(Wong y Pang, 2000).

De esta manera las enfermeras(os) chinas(os) tienen la obligación de seguir las creencias de los habitantes de su país y tratarlos con respeto y sinceridad. Pang (2000) ha descrito que las enfermeras se pueden introducir conceptualmente en la esfera familiar del paciente e, incluso, actuar como una familia sustituta, proceder que aumenta la confianza del paciente, quien no se siente tan estresado porque lo atienda un desconocido.

\section{Salud ocupacional para las enfermeras chinas}

No hace mucho tiempo, según Shin, Shin y Li (2002), se han generado varios temas de salud ocupacional que afectan a los departamentos de enfermería: enfermedades en la piel (especialmente en manos), desórdenes músculo-esqueléticos (particularmente dolor de espalda), debido a las largas jornadas de trabajo y al trabajo pesado por la gran cantidad de pacientes en cama que existen, lo cual causa que la persona obtenga poca ventilación natural y mucho estrés por ruido que también afecta al personal de enfermería. Otros grandes peligros a los que se enfrentan, se refieren a los pinchazos y a lesiones punzocortantes.

\section{Retos en la enfermería china}

Existen al menos 1.2 millones de enfermeros y enfermeras en China; no obstante, la proporción entre ellos y los habitantes es muy baja, debido a que apenas hay 98.6 enfermeras(os) para 100000 habitantes, desproporción que aumentó, puesto que antes solo había 0,5 enfermeras(os) para 100000 habitantes; entonces, 
el reto consiste en aumentar la cantidad de enfermeros para que esta desproporción cambie y se brinde una atención integral a los pacientes.

Otro reto que se debe alcanzar es aumentar la calidad de la educación en enfermería, dado que contribuirá a que los pocos enfermeros que existen ayuden a formar una mayor cantidad de nuevos enfermeros, máxime que "como la gran mayoría sólo tienen un grado de asociado o diplomado en enfermería, también hay una necesidad urgente de reducir la brecha en el nivel de la educación entre China y otros países desarrollados como por ejemplo Australia y Japón" (Chan y Wong, 1999).

Entre otros problemas se detecta la rápida entrada de pacientes y la desconocida naturaleza de los síndromes respiratorios agudos severos (SARS), considerados los nuevos retos por vencer desde la enfermería china. Una de las prioridades es usar toda la capacidad nacional para diagnosticar, tratar y prevenir tales infecciones; sin embargo, muchos profesionales se ven afectados, dado que al movilizarse para tratar dichas enfermedades, pierden sus vidas.

\section{Enfermería en la actualidad}

Según Smith y Tang (2004), la enfermería china debe abrirse más al mundo para que su desarrollo sea paralelo al de otros países, más si se considera que las escuelas y los hospitales de entrenamiento para enfermería son inadecuados para preparar enfermeras competentes. Aparte, en Hong Kong no hay una política gubernamental clara relacionada con el futuro desarrollo de la educación en enfermería. En China los estudiantes de enfermería son muy jóvenes, siguen inmaduros en muchos aspectos; por ende, cuando se involucren en el trabajo no van a ser capaces de satisfacer las necesidades psicológicas de los pacientes (Smith y Tang, 2004).

\section{CONCLUSIONES}

Las filosofías y religiones chinas permean la forma de vivir y pensar respecto de la salud y su cuidado dentro de la sociedad china. Por lo tanto, las enfermeras deben combinar la información de su cultura y la valoración clínica del paciente para otorgar un cuidado integral.

Una buena manera de combinar los valores chinos y occidentales dentro del sistema de cuidado consiste en conjugar los valores tradicionales, mientras se respeta la elección individual o personal.

La fundación filosófica china y la tradición estética, en combinación con la ciencia occidental, son trascendentales para los futuros avances en la investigación de enfermería, amalgama de la que se beneficiará Asia y el mundo entero. 


\section{Revista Electrónica Enfermeria Actual en costa Rica}

\section{REFERENCIAS}

Blanco, F. (2013). La enfermería en China. Entrevista personal directa.

Chan, S., y Wong, F. (1999). Development of basic nursing education in China and Hong Kong. Journal of Advanced Nursing, 29(6),1300-1307.

Chen, K. (1996). Nursing History Review. Official Journal of the American Association for the History of Nursing, 4, 129-149.

Chen, Y. (2002). Chinese values, health and nursing. Journal of Advanced Nursing, 36, 270-273.

Chiu, T. Y. \& Lee S. T. (1996). Development of basic nursing education in China. Proceedings of the First China Hong Kong Nursing Education Conference. The Hong Kong Polytechnic University. Hong Kong.

Davis, A. J.; Gan, L. J.; Lin, J. Y. \& Olesen, V. L. (1992). The young pioneers: first baccalaureate nursing students in the People's Republic of China. Journal of Advanced Nursing, 17, 1166-1170.

Davison, J. (2005). The Challenge of Learning the Chinese Language. Recuperado de http://www.chinatownconnection.com/learning_chinese.htm, el 15 de Junio de 2013.

Donahue, M. P. (1993). NURSING:The Finest Art.(1ra ed.). Missouri, Estados Unidos: The C.V. Mosby Company. pp. 2-137.

Escuela de Enfermería. (2013). Desarrollo sociohistórico y epistemológico de la Enfermería. Plan de Estudios, Escuela de Enfermería, Universidad de Costa Rica: San Pedro, CR.

Iammarino, N. K. (1983). Health education in schools. The Journal of School Health, Feb, 104-108. JournalofAdvancedNursing, 6, 1300-1307.

Lincona, M., Sánchez, G., Vásquez, M., Villanueva, J. y Mak, K. (2010). Chinese culture. Recuperado el 26 de Mayo del 2013, de http://nursing322sp10.wordpress.com/chinese- culture/

Meilian, L. (2013). Internacional shortage sees Chinese nurses in high demand. Recuperado de http://www.globaltimes.cn/content/764024.shtml, el 15 de Junio de 2013.

Oldnall, A. (1995). Nursing as an emerging academic discipline. Journal of Advanced Nursing. $21,605-612$.

Organización Mundial de la Salud (OMS). (2004). Indicadores de Salud en China. Recuperado de http://www.who.int, el 15 de Junio de 2004.

Parentini, M. (2002). Historia de Enfermería: Aspectos Relevantes desde sus orígenes hasta el siglo XX. 
Montevideo: Ediciones Trilce.

Rae, S.; Rim, K. \& Yu, C. (2002). Nursing Education Systems in Korea, China and the United States of America and its Future Directions. Journal of Korean Academy of Nursing. 32(7), 949-959.

Shin, S., Shin, K. y Li, C. (2002). Nursing Education Systems in Korea, China and the United States of America and its Future Directions. Journal of Korean Academy of Nursing, 32, 949-959.

Smith, D. y Tang, S. (2004). Nursing in China: Historical development, current issues and future challenges. Journal of Oita Nursing and Health Sciences, 2, 16-20.

Wong, M. (2007). How Traditional Chinese Health Beliefs and Chinese Culture Influence Health and Illness? Recuperado de http://ezinearticles.com/?How-Traditional-Chinese-Health-Beliefs-and-Chinese- CultureInfluence-Health-and-Illness?yid=903741

$\mathrm{Xu}, \mathrm{Y} . \&$ et al. (2000). The nursing education system in the People's Republic of China: Evolution, structure and reform. International Nursing Review, 47, 207-217.

Yu, X. (1989). Eighty Years of History of Chinese Nursing Association. Chinese Nursing Association, Beijing. 